\title{
Prevention of Ventilation Associated Pneumonia, New Ideas and Better Results
}

\section{Amir S Matta*}

Department of Pulmonary and Critical Care Medicine, Bronx University, USA

\begin{abstract}
The ventilation associated pneumonia is one the biggest challenge in the critical care team. It has a high mortality rate and an increase cost of the management. The use of the antibiotics did not show a great improvement in the survival rate. On the other hand, the prevention of ventilation associated pneumonia shows promising results, it improves the survival rate, decease both days of antibiotic use and days in the critical care unit. In the last 10 years, different methods used for the prevention of ventilator associated pneumonia. Some of those methods show a promising results while others need do not.
\end{abstract}

We reviewed different methods of prevention including oral hygiene, probiotics, cuff pressure control, subglottic secretion drainage, endotracheal cuff, coated endotracheal tube, and the multisystem approach. We review the papers and the data supplement online, and we compared between the different methods in the short outcome, long outcome, length of stay in the ICU, and the cost of the management.

Keywords: Ventilator associated pneumonia; High volume low pressure; Subglottic secretion drainage

\section{Introduction of the Prevention of Ventilation Associated Pneumonia}

Ventilator Associated Pneumonia (VAP) is defined as parenchymal infection of the lung occurring in a patient who has been assisted by mechanical ventilation within the past 48 hours, the morbidity and mortality of VAP makes it one of the biggest challenging cases in the critical care unit. VAP incidence is $25 \%$ of all critical care unit infectious diseases, and $10-25 \%$ of ventilated cases develop VAP, $>25 \%$ of antibiotics prescribed in ICU are for VAP patients [1], VAP increases the length on mechanical ventilation, and ICU stay, longer hospital length of stay, all of those parameters increases the cost of VAP cases by $\$ 40,000$ [2]. VAP increase the mortality rate by double [3].

The prevention of VAP shows promising results further than decreasing incidence of VAP. There are several ways has been introduced in the prevention of VAP and become much more complicated than old methods. The sources of the VAP have been identified in several places such as oral cavity [4], subglottic fluid [5], and the gastric mucosa [6].

The endotracheal tube shows an important matter in the development of VAP, as a source of infection and as a reservoir of the infection from the formation of the biofilm on the inner surface of tube [7]. The subglottic fluid, leakage, and micro aspiration has been identified as a source of VAP, different new ways has been introduced to the endotracheal tube to prevent VAP, including new designs of the cup, and suction of the subglottic fluid [8].

We have reviewed the new different ways in the prevention of VAP, in several ways including the incidence of VAP as a primary outcome and the mortality rate, duration of mechanical ventilation, ICU stay as a secondary outcome. Those new methods of VAP prevention include the Oral hygiene, probiotics, cuff pressure control, subglottic aspiration fluid, endotracheal cuff, coated endotracheal tube, and the use of multi system approach.

\section{Oral Hygiene}

Dental plaque is a complex and dynamic biofilm that forms on supragingival and subgingival tooth surfaces, oral mucosal surfaces (especially tongue), and dental restorations [9], there are over 700 bacterial species identified in the oral cavity, with more than 400 are present in periodontal pocket [10], Dennesen et al. reveals that absence of adequate salivary flow in intubated patients in ICU may contribute with the development of oropharyngeal colonization, by molecular analysis of the oral and respiratory bacteria in VAP patients, it is shown that $88 \%$ of the cases of VAP had an overlap of pathogens in the lung and the oral cavity [4].

The effect of the oral hygiene is proved by Mori et al. there was a significant reduction in the incidence of VAP (episodes of pneumonia per 1000 ventilator days) with oral care comparing with non-oral care $(\rho<0.001,3.9$ vs. 10.4$)$ by using $300 \mathrm{ml}$ weakly acidic water, and swab diluted povidone iodine 3 times a day. There is also a significant reduction in the most pathogenic organisms causing VAP in the oral cavity such as Pseudomonas aeruginosa, Methilin resistant $S$ aureus, and Gram negative bacteria (Enterobacteriaceae, Acinetobacter etc). This effect of the oral hygiene is significant on the early onset of VAP $(\mathrm{RR}=0.08,95 \% \mathrm{CI} ; 0.02-0.27)$, but there is no significant decrease in the late onset VAP ( $\mathrm{RR}=0.66,95 \% \mathrm{CI}$ : $0.34-1.28)$ between the oral care and non-oral care [11].

The chlorhexidine is cationic agents that exhibit the bacterial activity through alteration of the membrane causing interferes on the osmotic balance and metabolism. The use of antiseptic oral care for the prevention of VAP (chlorhexidine) was introduced by Genuit et al. in 2001, Genuit studied 95 cases comparing by adding chlorhexidine oral antiseptic to the weaning protocol in the prevention of VAP, the results shows a significant reduction of the incidence of VAP, and median duration of mechanical ventilation by $40 \%$ (4.5days, $\mathrm{p}<0.008$ ) comparing with the regular weaning protocol [12].

*Corresponding author: Amir S Matta, Department of Pulmonary and Critical Care Medicine, Bronx University, USA, Tel: +1(347)2516781; E-mail: amir.matta80@yahoo.com

Received October 08, 2014; Accepted February 02, 2015; Published February 05, 2015

Citation: Matta AS (2015) Prevention of Ventilation Associated Pneumonia, New Ideas and Better Results. J Pulm Respir Med 5: 240. doi: 10.4172/2161-105X.1000240

Copyright: (c) 2015 Matta AS. This is an open-access article distributed under the terms of the Creative Commons Attribution License, which permits unrestricted use, distribution, and reproduction in any medium, provided the original author and source are credited. 
The effect of use of the chlorhexidine in the prevention of VAP, comparing to regular oral care is controversial. Kusahara et al. studied 96 cases comparing the development of VAP between the use of regular oral care and the use of chlorohexidine, there was no benefit effect from oral care with $0.12 \%$ chlorhexidine, the development of VAP in regular oral care was about 16 cases, while the incidence of VAP with the chlorohexidine is 15 cases $(\mathrm{p}=0.949)$ [13], that is supported by the meta analysis of Pineda et al. who fails also to find any statistical clinical benefits of the use of chlorhexidine for the prevention of VAP, (odds ratio of 0.42; 95\% confidence interval 0.28-2.11) [14]. But the meta-analysis done by Kola et al. and Chan et al. proving that antiseptic oral chlorhexidine decontamination is effective at preventing of VAP in patients who receive mechanical ventilation for a short period (less than $48 \mathrm{~h}$ ), but has no effect on the overall mortality, duration of the mechanical ventilation or the duration of stay in the critical care $[15,16]$.

The use of the toothbrush and it is effect on the incidence of the VAP was studied by Lorenete et al. He studied 436 ICU patients, divided into two groups, 217 patients received oral care with tooth brushing, and 219 patients received oral care without tooth brushing. He found that there is no statistical significant between the two groups in the incidence of VAP ( 21 of 217 [9.7\%] with tooth brush use vs. 24 of 219 [11.0\%] without tooth brush, Odds ratio $=0.87, \mathrm{p}=0.75$ ) [17], this is also proved by the meta analysis done by Wan-Jie et al. He also proved that oral care with tooth brushing was not associated with decreased mortality rate (RR $0.88,98 \%$ CI 0.70 to $1.10, \mathrm{p}=0.26$ ), or decrease the duration of the mechanical ventilation $(\mathrm{p}=0.31)$, or antibiotic free days $(\mathrm{p}=0.29)$ [18].

We can conclude that the oral hygiene is effective in decreasing the incidence of early VAP but not the late onset VAP, while comparing the use of chlorhexidine and the toothbrush in the oral care to the regular oral care has shown no statistical difference in prevention of VAP.

\section{Probiotics}

Probiotics are living microbial agents of human origin that are able to tolerate the hostile gastrointestinal environment (acid and bile) such that they ultimately persist in the lower alimentary tract to confer health benefits to the host [19]. Probiotics can decrease the inflammatory reaction and improve both the immunological response (the balance between T-helper 1 and T-helper 2 cells), and immunological barrier of the gut $[20,21]$. The aspiration is one of the pathogenesis of the development of VAP [6], and the bacterial colonizations in the oral cavity and gastric fluid are one of the possibilities of the causative organisms for the VAP.

Morrow et al. has shown that there is a significant reduction of the oropahyrngeal and gastric colonization after use of nasogastric capsule and oropharynx with Lactobacillus rhamnosus probiotics comparing to placebo, that decrease reflects on the incidence of VAP, that there is a significant decrease in the incidence of VAP between placebo (incidence of $45.2 \%$ incidence; 95CI), and probiotics (23.3\% incidence; 95\% CI; $\mathrm{P}=0.005$ ), microbiologically, there is a significant reduction of VAP caused by Gram negative organisms $(\mathrm{P}=0.002)$, while there is no decrease in the VAP incidence caused by the Gram positive bacteria. Comparing to other methods in the prevention of VAP, the use of probiotics has a significant reduction in antibiotics used for C. difficile causing diarrhea $(\mathrm{P}=0.002)$. But regarding other parameters, there is no decrease in the duration of the mechanical ventilation, antibiotic consumption, hospital stay, ICU stay, or the mortality rate [22], that is also supported by I. Siempos et al. who studied 5 randomized controlled trials, he showed that there is a significant decrease in the incidence of
VAP between the control group and the group treated with probiotics (689 patients; fixed effect model: OR, 0.61; 95\% CI, 0.41-0.91; random effects model: OR, $0.55 ; 95 \% \mathrm{CI}, 0.31-0.95$ ), also there is no episodes of bacteremia attributable to the probiotic regimen [23].

On the other hand, Gu et al. and Watkinson et al. have two different meta-analysis of the use of the probiotics in the prevention of VAP, Gu et al. studied 7 randomized control trials showing that there is not a significant reduction in the VAP incidence (OR, 0.82; 95CI, 0.55-1.24; $\mathrm{P}=0.35$ ). Watkinson et al. has analyzed 18 randomized controlled trials, showing that there is no significant change with the use of probiotics $1.40(0.75-2.64)[24,25]$.

Our opinion about the use of the probiotic in prevention of VAP is still under analysis, as the results are controversial, and statistics did not show a clear results about different parameters such as the incidence, the days in the hospital, the use of the antibiotics.

\section{Cuff Pressure Control}

The cuff pressure is a challenging problem, as the cuff pressure is important to prevent the leakage of the subglottic fluid and the micro aspiration in the lower respiratory tract causing VAP, but if it is over inflated, it also may cause tracheomalasia, and injury to the tracheal mucosa when it is inflated over the capillary pressure. In addition, the cuff pressure is hard to be maintained with the therapeutic range. Nseir et al. has studied the variation of the endotracheal cuff pressure. $\mathrm{He}$ proves that the underinflation of the endotracheal cuff increases over the $8 \mathrm{~h}$ recording period, also the presence of sedation is considered a risk of under inflation [26].

The relation between the cuff pressure and development of ventilator associated pneumonia was introduced by Rello et al. who studied 83 intubated cases, undergoing continuous aspiration of subglottic secretions (CASS), he reveals that persistence intra cuff pressure below $20 \mathrm{H}_{2} \mathrm{O}$ considered a risk factor for development of VAP $(\mathrm{RR}=2.57$; $95 \% \mathrm{CI}=0.78$ to 8.03 ) [27]. On the other hand, Dullenkopf et al. studied in vitro different pressure levels on the leakage on different tubes of cuff tubes, he proves that the use of tube with polyurethane micro cuff is successful to prevent the leakage when it is inflated pressure around $30 \mathrm{~cm} \mathrm{H}_{2} \mathrm{O}$ [28]. In order to maintain the cuff pressure, Sole et al. has introduced a protocol to maintain the endotracheal cuff pressure within the therapeutic range, by identifying a higher target starting point pressure as the cuff pressure will be decreased by $2 \mathrm{~cm} \mathrm{H}_{2} \mathrm{O}$ when attaching a cufflator to the pilot balloon, then continuous monitoring or an automatic regulating device is attached [29].

The use of the cuff pressure controller shows a significant effect on the prevention of VAP, Nseir et al. has compared the use of a pneumonic device to maintain the tracheal cuff pressure to control group has shown that there was a significant decrease in the bacterial concentration in the tracheal (mean \pm SD $1.6 \pm 2.4$ VS. $3.1 \pm 3.7$ $\log 10 \mathrm{cfu} / \mathrm{ml}, \mathrm{p}=0.014$ ), and also there is a decrease in VAP incidence (9.8VS $>26.2 \% ; \mathrm{p}=0.032$ ), Nseir explains that decrease in VAP incidence is mainly due to the decrease of the aspiration of gastric fluid, as there is a decrease in the pepsin level in the tracheal secretion in the automatic pressure controller group comparing to the control group $(\mathrm{p}=0.04)$ [30].

Another study done by Valencia et al. who has studied the effect of the use of the cuff pressure controller in prevention of VAP, Valencia has proved that the cuff pressure is better controlled with automatic device ( $\mathrm{p}=0.001$ ) but this does not affect the incidence of VAP, that is explained by Valencia as they did not systematically perform cultures of oropharyngeal and tracheobronchial secretions and that affect the results of the experiment [31]. 
We think that inflation and maintaining the cuff pressure around 30 $\mathrm{cm} \mathrm{H}_{2} \mathrm{O}$ is suitable for preventing the leakage of the subglottic secretion into the trachea and thus decreasing the incidence of the VAP.

\section{Subglottic Secretion Drainage (SSD)}

The presence of secretion in the subglottic space is proven to be a source of aspiration in the intubated patients [8]. The subglottic secretion leakage occurred between the cuff and the trachea through the longitudinal folds towards the lungs [5,32] or through the micro aspiration of the subglottic secretions; both are proved to be causes of VAP. The subglottic secretion drainage (SSD) is a safe procedure that used to prevent the accumulation of the subglottic secretion.

Lacherade et al. has studied the effect of SSD on the incidence of VAP. A total of 333 cases in a randomized control clinical trial, SSD was associated with decrease in the incidence of the cases of VAP by half, the total number of VAP was 67, 25 of $169(14.8 \%)$ in SSD group, and 42 of $164(25.6 \%)$ in the control group $(\mathrm{p}=0.02, \mathrm{RR}=42.2 \%, 95 \% \mathrm{CI}$, 10.4-63.1\%) [33].

Lacherade et al. reveals that there is a decrease in both early and late onset of VAP, the results of the early VAP show that 2 of $169(1.2 \%)$ in the SSD group, and 10 of $164(6.1 \%)$ of the control group ( $\mathrm{p}=0.02)$, also the incidence of late onset of VAP decreased, 23 of $126(18.6 \%)$ of SSD group, 32 of 97 (33\%) of the controlled group ( $\mathrm{p}=0.01)$ [33]. On the other hand, Bo et al. [34], Wang et al. [35] and Dezfulian et al. [36], published papers show that there is no statistical significant in late onset VAP. Wang et al. reveals that SSD significantly reduced early onset VAP $(\mathrm{RR}=0.23,95 \% \mathrm{CI}: 0.13-0.43, \mathrm{p}<0.00001)$, while late onset of VAP (RR=1.15, 95\% CI: 0.51-2.61, p<0.73) [35], Dezfulian suggests that SSD is ineffective in preventing late onset VAP because $P$. aeruginosa and other Gram negative bacilli, can colonize the trachea without first appearing in the oropharyngeal or subglottic secretions, possibly through adhesion to endotracheal tube biofilm, that indicate that microaspiration may be less relevant to the pathogenesis of pneumonia with these organisms [36]. On the other hand Bo et al. [34] proves that there is a decrease in the incidence of VAP with SSD $(\mathrm{P}<0.05)$ and indicates that the efficacy is due to significant reduction caused by Gram-positive cocci and Haemophilus influenzae organisms.

Emilio Bouza et al. shows that the incidence of VAP in post cardiac surgery was decreased with use of continuous SSD comparing with control group, he studied 714 cases. 359 receive continuous SSD, while 331 as a control, for patients those receive MV for more than 48 hours, incidence of early VAP in SSD is $26.7 \%$, while the incidence of VAP in control was $47.5 \%$, $(R R=0.40 ; 95 \% C I, 0.16-0.99 ; p=0.04)$, also there is a significant reduction in the antibiotic use, determined as daily defined doses (DDD), as DDD in SSD group comparing to the control $(1,206.5$ vs. $1,877.5 ; \mathrm{p}<0.001)$ [37].

The effect of SSD is further than decreasing the VAP incidence; there is a significant shorten of the mechanical ventilation (by 1.55 days), and delayed the onset of VAP [35], stay in the ICU (about 3 days) for patient with SSD $[36,38]$, Those effects are reflected on the cost as well, despite the use of SSD tube costs $\$ 14$ more than usual ETT, SSD saves around $\$ 4,000$ saved per case [39].

The optimal suction pressure is between 20 and $30 \mathrm{mmHg}$ but the clinical variation should be considered, those pressures are sufficient to keep the suction efficient in removing the subglottic secretion specially when there is a viscoid secretion [40], the suction may be continuous or intermittent, it has been proved that both continuous and intermittent has the same effects in the prevention of VAP $[35,36]$, the continuous suction has problems with the mucosa causing herniation of the of the tracheal mucosa into the suction part leading to block of the suction system especially with high suction pressure [41]. While the intermittent suction is better in the mucosal injury, although in the time between the suctions, there may be some leakage between the folds of the cuff and the tracheal causing late onset VAP.

From previous studies, SSD has proved the efficacy in decreasing the early VAP incidence, days on ventilations and use of antibiotics. Both continuous and intermittent suction have proved their efficacy in decreasing the VAP incidence, while the use of intermittent suction is less side effects regarding the mucosal injury and block the suction system.

\section{Endo Tracheal Cuff}

The endotracheal tube cuff plays a role in the development of the VAP, as the leakage could happened between the cuff and the tracheal causing pneumonia, that leakage can occur in between the fold of the cuff and the trachea [42]. On the other hand, the use of high pressure cuff impairs the mucosal blood flow and mucosal damage to the tracheal mucosa. High volume low pressure (HVLP) cuff was introduced by Seegobin et al. as a safe procedure that it safes the tracheal mucosa from damage [43]. Unfortunately, HVLP cuff has failed to prevent the leakage of the subglottic fluid $[42,44,45]$.

Different types of Cuff was introduced to achieve both the prevention of the leakage of the subglottic fluid with no impairment of the tracheal mucosa, the use of the low-volume low-pressure cuff (LVLP) was studied by Peter Young et al. He studied different types of tubes in both vivo and in vitro, he shows a significant decrease in the leakage in LVLP tubes $(\mathrm{p}=0.01)$ and also there is a decrease in the incidence of VAP comparing with HVLP cuff [45]. Also the use of pressure limited cuff (PLC) such as silicon cuff prevents the leakage of the subglottic secretion into the lungs $[42,46]$. It also reveals a significant decrease in the incidence of VAP, comparing with HVLP cuffs [44].

Another way to prevent the leakage of subglottic secretion is the micro cuff (polyurethane cuff), the micro cuff tubes with a special cuff design of an ultrathin membrane $(7 \mu \mathrm{M})$, while the regular cuff membrane is about $(50 \mu \mathrm{M})$, the polyurethane cuff tubes designed to prevent the longitudinal folds with inflated within the trachea. Dullenkof compares the ultrathin cuff tube with the regular HVLP tube in vitro, he shows the polyurethane cuff tube prevents the leakage of fluid when pressure inside the cuff is set $30 \mathrm{cmH}_{2} \mathrm{O}$ [28], Miller et al. studied the effect of ultrathin polyurethane cuff on the VAP incidence. He studied 3207 patients of total 16,223 days of ventilation, the incidence of VAP in Polyurethane cuff tube was 2.8 VAP rate per 1000 ventilator days, while the VAP incidence of VAP in patients with regular endotracheal tube is 5.0 per 1000 ventilator days $(\mathrm{p}=0.027)$ [47]. Also, in the cardiac surgery, Poelaert et al. studied 134 patients, 67 cases with polyurethane cuff and 69 cases as a control, there is a significant reduction in the incidence of VAP (28 vs. 15, p=0.026) [48].

Combination between the polyurethane cuff and the subglottic secretion drainage has magnificent results, that there is a significant decrease in total VAP incidence $(\mathrm{p}=0.001)$, early onset VAP $(\mathrm{p}=0.02)$ and late onset VAP ( $\mathrm{p}=0.01$ ) with the SSD with polyurethane micro cuff endotracheal tube, comparing with regular endotracheal tube [49].

We can conclude from the previous studies that HVLP failed to decrease the incidence of VAP while both the LVLP cuff and the micro cuff are effective in decreasing the incidence of VAP, by decreasing the leakage between the cuff and the trachea. 


\section{Coated endotracheal Tube}

The formation of the biofilm is so early after the intubation [50]. And it has a role in the pathogenesis of VAP. The biofilm is a source and reservoir of infection to the lower respiratory tract [7], and a source of the contamination of the respiratory circuits [51], and it is resistance to the effect of the antibiotic [52]. The formation of the ETT biofilm may cause bacterial persistence and impairment of the antibiotic response [53]. The stage of the biofilm is associated with the incidence of VAP, as there is an increased incidence of VAP, at stage IV biofilms when there are floating bacteria and the glycocalyx begin to break down, those can lead to dislodge of the bacteria to the lower respiratory tract causing VAP [54]

The effect of the silver on the development of biofilm shows that the silver coated tubes have an effect in reduction of the formation of the biofilm, as after $16 \mathrm{~h}$ of intubation there is no formation of the biofilm in the coated tubes, while the biofilm is formed on a non-coated tubes just after $8 \mathrm{~h}(\mathrm{p}=0.001)[51,55,56]$.

The use of the silver coated tubes has no additional adverse effects on the patients while it shows a decrease in the incidence of VAP (in both early onset and late onset pneumonia), comparing with noncoated tubes, that decrease is around $50 \%$, also there is a delayed occurrence of VAP and a decrease in the use of the antibiotic use in the silver coated endotracheal patients comparing to regular endotracheal tube $[57,58]$, but there is no decrease in the ICU stay, hospital stay, or the mortality rate between them [58].

The use of silver coated tubes proves a decrease the incidence of the VAP for both early and late onset by prevention of formation the biofilm on the tube. But the limitation for the use of Silver coated tubes is mainly there is no decrease in other parameters including the days on ventilation, days in ICU.

\section{The Multisystem Approach}

Institute of Healthcare Improvement develop the concept "bundle" to improve in the outcome of the patients on ventilator, bundle means A bundle is a structured way of improving the processes of care and patient outcomes: a small, straightforward set of evidence-based practices generally three to five that, when performed collectively and reliably, have been proven to improve patient outcomes.

Rosenthal et al. studied the effect of several factors together in the incidence of VAP, including infection control measures, education, outcome surveillance, process surveillance, feedback of VAP, and performance feedback of infection control process. Those factors placed into a bundle of measures as follows (active surveillance for VAP, adherence to hand hygiene guidelines, semi-recumbent position, daily assessment for waning and weaning protocols, oral care, noninvasive ventilation as possible, oro-tracheal instead naso-tracheal, endotracheal cuff pressure at least $20 \mathrm{mmH}_{2} \mathrm{O}$, removal the condensate from the ventilator circuits, change ventilator circuits only when visible soiled or malfunctioning, avoid gastric over distension, avoid $\mathrm{H}_{2}$ blocker agents and proton pump inhibitors, use of sterile water to rinse reusable respiratory component. He studied this approach on 55,507 adult patients in 44 intensive care units of 127,374 ventilator days. The study was designed in 2 phases, phase 1 , baseline period the infection control team conducted prospective surveillance of VAP, and phase 2 which included the multidimensional approach. The results shows that there is a significant decrease in the VAP rate in 1000 mechanical ventilator days comparing phase 1 to phase 2 (22.0 vs. 17.2, $\mathrm{RR}=0.78(0.68-0.90), \mathrm{p}<0.0004)$, also there is a significant decreased rate of VAP in 100 patients (5.8 vs. $4.2, \mathrm{RR}=0.73(0.64-0.84)$, $\mathrm{p}<0.0001$ ), while is no decrease in the mortality rate between the 2 phases [59].

Cachecho et al. studied the effect of the bundle on the rate of VAP in the trauma patients, VAP bundle included head elevation 30 to 45 degrees, mouth hygiene every 6 hours with chlorhexidine, gastrointestinal bleeding prophylaxis, daily assessment of weaning, daily assessment of sedation appropriateness, and daily drug holiday when not contraindicated, Cachecho et al. compares outcome of trauma patients between January 2005 and December 2006 (P1), while P2 from 2007 to 2009, with total cases 954 . The results reveals that there is a significant decrease of duration on ventilation in P2 compared to P1 (21.52 \pm 15.40 vs. $18.88 \pm 10.98, \mathrm{p}<0.05)$, while the VAP rate drops from 7.8/1,000 ventilator days in P1 to $1.4 / 1,000$ ventilator days in P2 $(\mathrm{p}<0.05)[60]$.

The use of bundles has shown a promising results in different hospitals and different countries. We think the use of bundles can be applied with effective decrease in the VAP incidence. The important part is the low cost to use the bundle thus it can be applied in most hospitals.

\section{Conclusion}

We have reviewed different methods and protocols to decrease the incidence of VAP, some of these measures (such as oral hygiene, endotracheal cuff material, cuff pressure control, subglottic secretion, coated tube) prove effectiveness in decreasing the incidence. Those measures has proved decrease incidence in the early onset pneumonia, while it did not prove to prevent the late onset pneumonia. We recommend more studies in the measures to decrease the late onset pneumonia as well, and more studies regarding the mechanical ventilation shorten, mortality rate, and length hospital stay. The cost of the preventive measures is important. The bundles have shown a decrease incidence with little cost although it did not provide information regarding the effectiveness in prevention of late VAP.

\section{References}

1. Craven DE (2006) Preventing ventilator-associated pneumonia in adults: sowing seeds of change. Chest 130: 251-260.

2. Rello J, Ollendorf DA, Oster G, Vera-Llonch M, Bellm L, et al. (2002) Epidemiology and outcomes of ventilator-associated pneumonia in a large US database. Chest 122: 2115-2121.

3. Safdar N, Dezfulian C, Collard HR, Saint S (2005) Clinical and economic consequences of ventilator-associated pneumonia: a systematic review. Crit Care Med 33: 2184-2193

4. Bahrani-Mougeot FK, Paster BJ, Coleman S, Barbuto S, Brennan MT, et al. (2007) Molecular analysis of oral and respiratory bacterial species associated with ventilator-associated pneumonia. J Clin Microbiol 45: 1588-1593.

5. Young PJ, Rollinson M, Downward G, Henderson S (1997) Leakage of fluid past the tracheal tube cuff in a benchtop model. Br J Anaesth 78: 557-562.

6. Atherton ST, White DJ (1978) Stomach as source of bacteria colonising respiratory tract during artificial ventilation. Lancet 2: 968-969.

7. Adair CG, Gorman SP, Feron BM, Byers LM, Jones DS, et al. (1995) Implications of endotracheal tube biofilm for ventilator-associated pneumonia. Intensive care medicine 25: 1072-1076.

8. Mahul P, Auboyer C, Jospe R, Ros A, Guerin C, et al. (1992) Prevention of nosocomial pneumonia in intubated patients: respective role of mechanical subglottic secretions drainage and stress ulcer prophylaxis. Intensive Care Med 18: 20-25.

9. ten Cate JM (2006) Biofilms, a new approach to the microbiology of dental plaque. Odontology / the Society of the Nippon Dental University 94:1-9.

10. Paster BJ, Olsen I, Aas JA, Dewhirst FE (2006) The breadth of bacterial diversity in the human periodontal pocket and othe oral sites. Periodontol 2000 42: 80-87. 
11. Mori H, Hirasawa H, Oda S, Shiga H, Matsuda K, et al. (2006) Oral care reduces incidence of ventilator-associated pneumonia in ICU populations. Intensive Care Med 32: 230-236.

12. Genuit T, Bochicchio G, Napolitano LM, McCarter RJ, Roghman MC (2001) Prophylactic chlorhexidine oral rinse decreases ventilator-associated pneumonia in surgical ICU patients. Surg Infect (Larchmt) 2: 5-18.

13. Kusahara DM, Peterlini MA, Pedreira ML (2012) Oral care with $0.12 \%$ chlorhexidine for the prevention of ventilator-associated pneumonia in critically ill children: Randomised, controlled and double blind trial. International journal of nursing studies 49: 1354-1363.

14. Pineda LA, Saliba RG, El Solh AA (2006) Effect of oral decontamination with chlorhexidine on the incidence of nosocomial pneumonia: a meta-analysis. Critical care 10: R35.

15. Chan EY, Ruest A, Meade MO, Cook DJ (2007) Oral decontamination for prevention of pneumonia in mechanically ventilated adults: systematic review and meta-analysis. Bmj 334: 889.

16. Kola A, Gastmeier P (2007) Efficacy of oral chlorhexidine in preventing lower respiratory tract infections. Meta-analysis of randomized controlled trials. J Hosp Infect 66: 207-216.

17. Lorente L, Lecuona M, Jimenez A, Palmero S, Pastor E, et al. Ventilatorassociated pneumonia with or without toothbrushing: a randomized controlled trial. European journal of clinical microbiology \& infectious diseases: official publication of the European Society of Clinical Microbiology 31: 2621-2629.

18. Gu WJ, Gong YZ, Pan L, Ni YX, Liu JC (2012) Impact of oral care with versus without toothbrushing on the prevention of ventilator-associated pneumonia: a systematic review and meta-analysis of randomized controlled trials. Crit Care 16: R190.

19. Guidelines for the evaluation of probiotics in food: report of a joint FAO/WHO working group on drafting guidelines for the evaluation of probiotics in food.

20. Isolauri E (2001) Probiotics in human disease. Am J Clin Nutr 73: 1142S-1146S.

21. Ghosh S, van Heel D, Playford RJ (2004) Probiotics in inflammatory bowe disease: is it all gut flora modulation? Gut 53: 620-622.

22. Morrow LE, Kollef MH, Casale TB (2010) Probiotic prophylaxis of ventilatorassociated pneumonia: a blinded, randomized, controlled trial. American journal of respiratory and critical care medicine 182: 1058-1064.

23. Siempos II, Ntaidou TK, Falagas ME (2010) Impact of the administration of probiotics on the incidence of ventilator-associated pneumonia: a metaanalysis of randomized controlled trials. Crit Care Med 38: 954-962.

24. Gu WJ, Wei CY, Yin RX (2012) Lack of efficacy of probiotics in preventing ventilator-associated pneumonia probiotics for ventilator-associated pneumonia: a systematic review and meta-analysis of randomized controlled trials. Chest 142: 859-868.

25. Watkinson PJ, Barber VS, Dark P, Young JD (2007) The use of pre- pro- and synbiotics in adult intensive care unit patients: systematic review. Clin Nutr 26: 182-192.

26. Nseir S, Brisson H, Marquette CH, Chaud P, Di Pompeo C, et al. (2009) Variations in endotracheal cuff pressure in intubated critically ill patients: prevalence and risk factors. Eur J Anaesthesiol 26: 229-234.

27. Rello J, Soñora R, Jubert P, Artigas A, Rué M, et al. (1996) Pneumonia in intubated patients: role of respiratory airway care. Am J Respir Crit Care Med 154: 111-115.

28. Dullenkopf A, Gerber A, Weiss M (2003) Fluid leakage past tracheal tube cuffs: evaluation of the new Microcuff endotracheal tube. Intensive Care Med 29: 1849-1853.

29. Sole ML, Su X, Talbert S (2011) Evaluation of an intervention to maintain endotracheal tube cuff pressure within therapeutic range. American journal of critical care: an official publication, American Association of Critical-Care Nurses 20: 109-117.

30. Nseir S, Zerimech F, Fournier C, Lubret R, Ramon P, et al. (2011) Continuous control of tracheal cuff pressure and microaspiration of gastric contents in critically ill patients. Am J Respir Crit Care Med 184: 1041-1047.

31. Valencia M, Ferrer M, Farre R, Navajas D, Badia JR, et al. (2007) Automatic control of tracheal tube cuff pressure in ventilated patients in semirecumbent position: a randomized trial. Crit Care Med 35: 1543-1549.
32. Ouanes I, Lyazidi A, Danin PE, Rana N, Di Bari A, et al. (2011) Mechanica influences on fluid leakage past the tracheal tube cuff in a benchtop model. Intensive Care Med 37: 695-700.

33. Lacherade JC, De Jonghe B, Guezennec P, Debbat K, Hayon J, et al. (2010) Intermittent subglottic secretion drainage and ventilator-associated pneumonia: a multicenter trial. American journal of respiratory and critical care medicine 182: 910-917.

34. Bo H, He L, Qu J (2000) [Influence of the subglottic secretion drainage on the morbidity of ventilator associated pneumonia in mechanically ventilated patients]. Zhonghua jie he he hu xi za zhi = Zhonghua jiehe he huxi zazhi = Chinese journal of tuberculosis and respiratory diseases 23: 472-474.

35. Wang F, Bo L, Tang L, Lou J, Wu Y, et al. (2012) Subglottic secretion drainage for preventing ventilator-associated pneumonia: an updated meta-analysis of randomized controlled trials. J Trauma Acute Care Surg 72: 1276-1285.

36. Dezfulian C, Shojania K, Collard HR, Kim HM, Matthay MA, et al. (2005) Subglottic secretion drainage for preventing ventilator-associated pneumonia: a meta-analysis. Am J Med 118: 11-18.

37. Bouza E, Pérez MJ, Muñoz P, Rincón C, Barrio JM, et al. (2008) Continuous aspiration of subglottic secretions in the prevention of ventilator-associated pneumonia in the postoperative period of major heart surgery. Chest 134: 938946.

38. Leasure AR, Stirlen J, Lu SH (2012) Prevention of ventilator-associated pneumonia through aspiration of subglottic secretions: a systematic review and meta-analysis. Dimens Crit Care Nurs 31: 102-117.

39. Shorr AF, O'Malley PG (2001) Continuous subglottic suctioning for the prevention of ventilator-associated pneumonia : potential economic implications. Chest 119: 228-235.

40. O’Neal PV, Munro CL, Grap MJ, Rausch SM (2007) Subglottic secretion viscosity and evacuation efficiency. Biol Res Nurs 8: 202-209.

41. Dragoumanis CK, Vretzakis GI, Papaioannou VE, Didilis VN, Vogiatzaki TD et al. (2007) Investigating the failure to aspirate subglottic secretions with the Evac endotracheal tube. Anesth Analg 105: 1083-1085, table of contents.

42. Young PJ, Basson C, Hamilton D, Ridley SA (1999) Prevention of tracheal aspiration using the pressure-limited tracheal tube cuff. Anaesthesia 54: 559563.

43. Seegobin RD, van Hasselt GL (1984) Endotracheal cuff pressure and tracheal mucosal blood flow: endoscopic study of effects of four large volume cuffs. $\mathrm{Br}$ Med J (Clin Res Ed) 288: 965-968.

44. Young PJ, Burchett K, Harvey I, Blunt MC (2000) The prevention of pulmonary aspiration with control of tracheal wall pressure using a silicone cuff. Anaesthesia and intensive care 28: 660-665.

45. Young PJ, Pakeerathan S, Blunt MC, Subramanya S (2006) A low-volume low-pressure tracheal tube cuff reduces pulmonary aspiration. Crit Care Med 34: 632-639.

46. Pavlin EG, VanNimwegan D, Hornbein TF (1975) Failure of a high-compliance low-pressure cuff to prevent aspiration. Anesthesiology 42: 216-219.

47. Miller MA, Arndt JL, Konkle MA, Chenoweth CE, Iwashyna TJ, et al. (2011) A polyurethane cuffed endotracheal tube is associated with decreased rates of ventilator-associated pneumonia. J Crit Care 26: 280-286.

48. Poelaert J, Depuydt P, De Wolf A, Van de Velde S, Herck I, et al. (2008) Polyurethane cuffed endotracheal tubes to prevent early postoperative pneumonia after cardiac surgery: a pilot study. J Thorac Cardiovasc Surg 135 771-776.

49. Lorente L, Lecuona M, Jiménez A, Mora ML, Sierra A (2007) Influence of an endotracheal tube with polyurethane cuff and subglottic secretion drainage on pneumonia. Am J Respir Crit Care Med 176: 1079-1083.

50. Rello J, Afessa B, Anzueto A, Arroliga AC, Olson ME, et al. (2010) Activity of a silver-coated endotracheal tube in preclinical models of ventilator-associated pneumonia and a study after extubation. Crit Care Med 38: 1135-1140.

51. Berra L, De Marchi L, Yu ZX, Laquerriere P, Baccarelli A, et al. (2004) Endotracheal tubes coated with antiseptics decrease bacterial colonization of the ventilator circuits, lungs, and endotracheal tube. Anesthesiology 100: 14461456.

52. Brown MR, Allison DG, Gilbert P (1988) Resistance of bacterial biofilms to antibiotics: a growth-rate related effect? J Antimicrob Chemother 22: 777-780. 
Citation: Matta AS (2015) Prevention of Ventilation Associated Pneumonia, New Ideas and Better Results. J Pulm Respir Med 5: 240. doi: 10.4172/2161-105X.1000240

53. Gil-Perotin S, Ramirez P, Marti V, Sahuquillo JM, Gonzalez E, et al. (2012) Implications of endotracheal tube biofilm in ventilator-associated pneumonia response: a state of concept. Crit Care 16: R93.

54. Wilson A, Gray D, Karakiozis J, Thomas J (2012) Advanced endotracheal tube biofilm stage, not duration of intubation, is related to pneumonia. J Trauma Acute Care Surg 72: 916-923.

55. Berra L, Curto F, Li Bassi G, Laquerriere P, Pitts B, et al. (2008) Antimicrobialcoated endotracheal tubes: an experimental study. Intensive Care Med 34: 1020-1029.

56. Hartmann M, Guttmann J, Muller B, Hallmann T, Geiger K (1999) Reduction of the bacterial load by the silver-coated endotracheal tube (SCET), a laboratory investigation. Technology and health care: official journal of the European Society for Engineering and Medicine 7: 359-370.
57. Kollef MH, Afessa B, Anzueto A, Veremakis C, Kerr KM, et al. (2008) Silvercoated endotracheal tubes and incidence of ventilator-associated pneumonia: the NASCENT randomized trial. JAMA : the journal of the American Medica Association 300: 805-813.

58. Berra L, Kolobow T, Laquerriere $P(2008)$ Internally coated endotracheal tubes with silver sulfadiazine in polyurethane to prevent bacterial colonization: a clinical trial. Intensive care medicine 34: 1030-1037.

59. Rosenthal VD, Rodrigues C, Alvarez-Moreno C (2012) Effectiveness of a multidimensional approach for prevention of ventilator-associated pneumonia in adult intensive care units from 14 developing countries of four continents: findings of the International Nosocomial Infection Control Consortium. Crit Care Med 40: 3121-3128.

60. Cachecho R, Dobkin E (2012) The application of human engineering interventions reduces ventilator-associated pneumonia in trauma patients. $J$ Trauma Acute Care Surg 73: 939-943. 